\title{
SOURCES AND ADAPTIVE CONSEQUENCES OF EGG SIZE VARIATION IN NEZARA VIRIDULA (HEMIPTERA: PENTATOMIDAE)
}

\author{
By Denson Kelly McLain*and Stephen Donald Mallard \\ Department of Biology \\ Landrum Box 8042 \\ Georgia Southern University \\ Statesboro, GA 30460
}

INTRODUCTION

Very little is known about the relationship in insects between female size and egg size (e.g. Price and Wilson, 1976; Wiklund and Karlsson, 1988) or how that relationship responds to selection pressures imposed by changing ecological and physiological environments (e.g. Moore and Singer, 1987). A few studies have, however, documented some of the fitness consequences of variation in egg size. For example, offspring from larger eggs may hatch more successfully (Richards and Meyers, 1980), develop more rapidly (Steinwascher, 1984), or attain larger size (Johnson, 1982).

Assuming that egg size is positively correlated with offspring fitness, an optimal egg and clutch size may evolve (Smith and Fretwell, 1974). The optimum may depend on the degree and nature of larval competition (Parker and Begon, 1986; Ives, 1989), relative safety of egg versus larval stages (Shine, 1989; Nassbaum and Schultz, 1989), or variation in quality of larval habitats (Capinera, 1979; McGinley et al., 1987). In addition, the optimum may vary from female to female within a population as a consequence of differences in body size and foraging efficiency (Parker and Begon, 1986; Shine 1988).

The present study documents egg size variation in the southern green stink bug, Nezara viridula L. (Hemiptera: Pentatomidae) and examines the life history consequences of such variation. Female size, mate size, egg mass number (i.e. first, fifth, tenth, or fifteenth mass laid), egg mass size, and location within the egg mass (inner

\footnotetext{
${ }^{*}$ To whom correspondence should be addressed.

Manuscript received 6 May 1991
} 
versus outer egg rows) are assessed for their contribution to variation in egg size. We also examine the correlation between egg size and offspring hatching success, ultimate adult size, probability of survival to adult stage, and development rate.

\section{MethodS}

\section{Collection and rearing.}

Southern green stink bugs, Nezara viridula, were reared in the laboratory from the eggs of 30 females collected in mid-April (1988 and 1990) from wild mustard growing in an abandoned pasture on SR 24, 6 miles north of its junction with US 80 in Statesboro, GA (USA). Each female was housed individually in a 1-liter jar supplied with 2 pole beans that served as both a food and water source. A strip of white paper towel was suspended from the rim of each jar as an oviposition substrate. Eggs were hatched in petri dishes containing pole bean onto which nymphs moved 1-2 d after hatching. Nymphs, in groups of 40, were reared in 4-liter cartons supplied with fresh pole beans and shelled, raw peanuts. Beans and peanuts were replaced every $5 \mathrm{~d}$. Insects were maintained on a 14L:10D photophase at $20-23^{\circ} \mathrm{C}$ and $80-85 \% \mathrm{RH}$.

Cartons with fifth instar nymphs were checked daily for adults which were then sequestered by sex. Because adults do not mate until they are over 1 week old (Harris and Todd, 1980), there was no opportunity for females to mate within rearing cartons.

\section{Mating and maintenance of females.}

One male and 1 female, each 10-d-old virgin adults, were placed in 1-liter jars that served as mating chambers. In all cases, the males and females that were housed together were derived from different mothers. Otherwise, individuals were assigned to mating chambers randomly and without regard to size. Each mating chamber was stocked with 2 pole beans. Once a pair had terminated copulation, the female was removed from the mating chamber to a $1 / 2$-liter carton (oviposition carton). Male and female size (width across the pronotum at the humeral angles) was measured to the nearest $0.125 \mathrm{~mm}$ with an ocular micrometer on a dissecting scope.

Females were allotted 1 month in which to initiate copulation. Mating activity was checked 1,6 , and $12 \mathrm{~h}$ into photophase. Since 
the duration of copulation averages 30-40 h (Harris and Todd, 1980 ) it is unlikely that many, if any, matings went undetected. No egg masses were found in mating chambers although over $60 \%$ of oviposition occurs within $1 \mathrm{~d}$ of the termination of copulation (Harris and Todd, 1980).

Once-mated females remained isolated in their cartons for the remainder of their lives. Cartons were restocked with a fresh pole bean every $5 \mathrm{~d}$ to prevent food/water supplies from drying out. White paper towel strips were suspended from carton rims as oviposition substrates. Cartons were checked daily for egg masses.

Egg size.

Egg diameter (= size) was measured to the nearest $0.01 \mathrm{~mm}$ with an ocular micrometer on a compound microscope at a magnification of 100X. In 1988, eggs were measured from the first, fifth, tenth, and fifteenth (if available) masses laid. Eighty females were included in this analysis of which 32 survived to lay $15 \mathrm{egg}$ masses. Five eggs were measured from each mass, two from the middle row of the mass, two from one of the outer rows, and one of unspecified location. Egg masses were typically hexagonal arrays of 50-100 eggs in 5-10 rows.

\section{Population density and egg size.}

An additional 72 females were permitted to mate under conditions of variable density ( 1 male $+1-7$ females). Upon initiation of copulation, the pair was removed and the female treated as outlined above. We measured the size of the female and the sizes of five eggs from the first egg mass laid by each female.

Egg size and offspring fitness.

In 1990, 5-10 outer row and 5-10 inner row eggs were taken from the first egg mass of 20 experimental females. Eggs were separated by hand and placed singly into 1-liter jars supplied with two pole beans. Hatch rate was $83.6 \%$. Beans were replaced every $5 \mathrm{~d}$ (=benign conditions). This rearing regime resulted in $29.3 \%$ mortality for nymphs that hatched. The egg size, time (d) from egg hatch to adulthood, and pronotal width were recorded for each individual surviving to adulthood. Egg and adult size were measured as before. 
Also, 5-10 inner and outer row eggs were separated from each of 15 initial egg masses and placed singly into 1-liter jars supplied with a pole bean. The pole bean in each jar was replaced every 7-9 d (=harsh rearing condition). This rearing regime resulted in $41.0 \%$ mortality. The egg size and survival of hatched nymphs to adulthood were recorded for each case.

The percent egg hatch depends upon humidity (unpublished observation). Thus, to determine the relationship between egg size and hatch rate under humidity-restricted conditions, some egg masses were incubated in petri dishes that did not contain pole bean (In the presence of beans in the petri dish the hatch rate is approximately $100 \%$ for fertilized eggs). Forty masses (first laid by each of 40 females) were developed under the humidityrestricted condition. Two unhatched eggs, one each from inner and outer rows were measured. An equal number of hatched eggs, positioned adjacent to unhatched eggs, were measured. The following scheme was employed to select eggs for measurement without bias: we chose the first unhatched egg and adjacent hatched egg that were at least 4 eggs in from the left margin of the row. Development without a bean resulted in less than 50\% hatch for fertilized eggs (Fertilization is evidenced by a change in egg color from cream to orange). A paired-difference t-test was used to determine if mean size differed between hatched and unhatched eggs.

\section{Statistical methods.}

For some analyses, egg sizes were converted to relative sizes (i.e., $y_{i j} / y_{\cdot j}$ where $y_{i j}$ is the size of egg $i$ of female $j$ and $y_{\cdot j}$ is the mean egg size for female $j$ ). Thus, variation in egg size associated with placement in the mass or associated with egg mass number (e.g. first versus tenth mass laid) is not confounded with variation between females in egg size.

The joint effects of independent variables on egg size were tested with multivariate general linear hypotheses of the form: egg size $=$ constant $+T_{1}+T_{2}+\ldots+T_{n}+E_{1}+E_{2}+\ldots+E_{n}$, where $T_{i}$ is a category variable (e.g., egg mass number) and $\mathrm{E}_{\mathrm{i}}$ is a continuous variable (e.g. female size). Statistical analyses were performed on a microcomputer using the Systat system for statistics (Wilkinson, 1987). In linear models, we report only variables contributing significantly to explained variation $\left(=\mathrm{R}^{2}\right)$. Absence of interaction 
terms connotes an absence of significance. Interaction between variance sources $\mathrm{I}$ and $\mathrm{J}$ is indicated as $(\mathrm{I})^{*}(\mathrm{~J})$ in models below. For univariate models, significance of the Pearson's correlation coefficient, $r$, is tested with a t-test (Edwards, 1985).

Since multiple eggs were measured or hatched for each female (mother) in 1988 and 1990, there is potential for degrees of freedom to be inflated by nonindependent data points. Therefore, all ANOVA tests and ANCOVA models include "mother" and its interaction terms as sources of variation to group data within females. This reduces the error degrees of freedom and increases the error mean square. The effects of "mother" and its interaction terms are reported only when significant $(\mathrm{P}<0.05)$.

For mutivariate analyses incorporating egg mass number as a source of variation, only data from females laying at least $15 \mathrm{egg}$ masses are used. This reduces the sample size from 80 to 32 mothers. Multivariate analyses of the effect of egg size on components of progeny fitness required at least four observations per sex of offspring per mother. This reduces the sample sizes to 10 or 12 mothers for tests on, respectively, females or male progeny.

\section{RESULTS}

Variation between females.

Egg size exhibits a relatively high degree of variation; the coefficient of variation in egg size $(\mathrm{CV}=5.75$ reflecting within- and between-female variation) was $98 \%$ as large as that for female size $(\mathrm{CV}=5.89)$. Models incorporating male size, female size, the interaction between male and female size, or total number of egg masses $(<15$ or $>15)$, either singly or in any combination, failed to explain a significant proportion of the variation between females in $\mathrm{CV}$ in egg size (For all models: $\mathrm{R}^{2}<0.02 ; \mathrm{P}>0.40 ; \mathrm{N}=80$ ).

Differences between females in egg size accounted for $57.2 \%$ of the total observed variation in egg size $(\mathrm{F}=17.15 ; \mathrm{df}=79,1012$; $\mathrm{P}<0.001)$. Female size accounted for $35.8 \%$ of the variation between females in lifetime mean egg size $(\mathrm{F}=35.91 ; \mathrm{df}=1,76$; $\mathrm{P}<0.001$; Fig. 1). Mate (male) size did not contribute to the explanation of variation in mean egg size across all masses $(\mathrm{F}=2.23$; $\mathrm{df}=1,74 ; \mathrm{P}=0.14$ when incorporated with female size in a linear model). Male size did explain a significant proportion of the between-female variation in egg size for the first mass laid after 


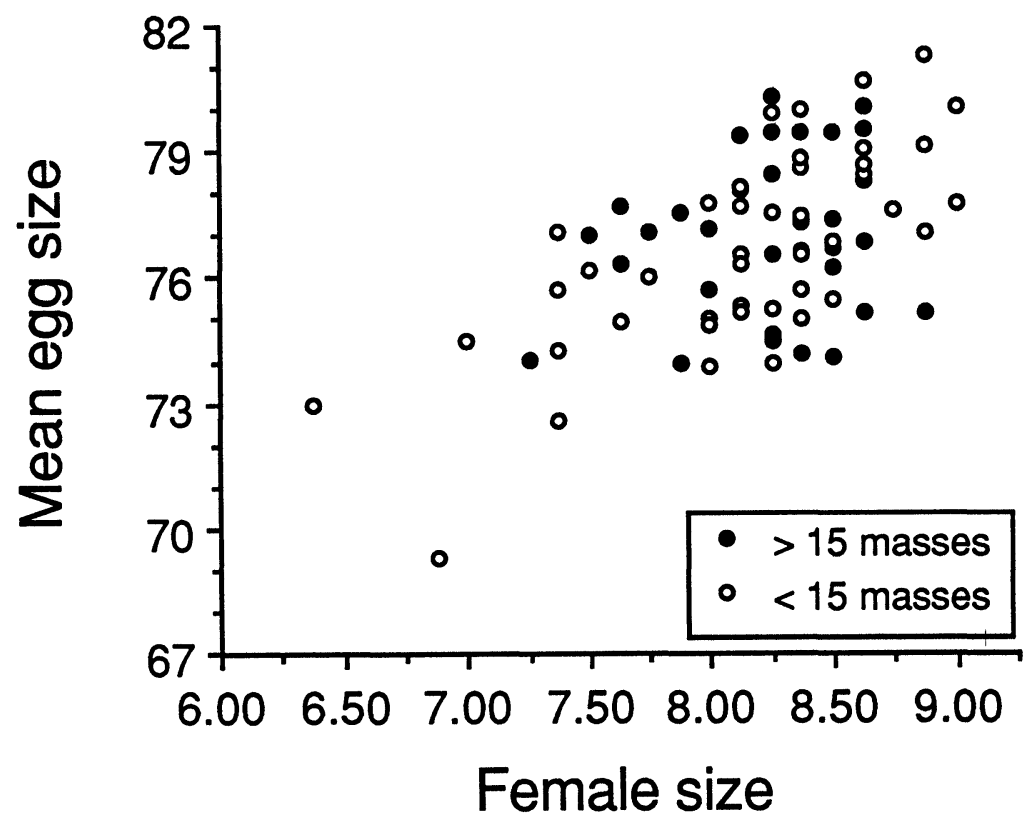

Figure 1. Correlation between female size (width $[\mathrm{mm}]$ at humeral angles) and lifetime mean egg size (diameter [0.01 $\mathrm{mm}$ units]).

copulation, but did not correlate with egg size in later masses (Table 1; Fig. 2).

When population density (no. bugs/container) and parent sizes are included in the analysis of mean egg size (first mass laid), the best model is mean $=$ constant + density $+($ female size $) *($ male size) $\left(\mathrm{F}=24.15 ; \mathrm{df}=2,71 ; \mathrm{R}^{2}=0.42 ; \mathrm{P}<0.001\right)$. Here, population density alone accounts for $25.7 \%$ of the variation $(\mathrm{F}=24.21 ; \mathrm{df}=1,72$; $\mathrm{P}<0.001)$ while the interaction between parent sizes contributes another $15.8 \%$ increment in explained variation in mean egg size $(\mathrm{F}=17.36 ; \mathrm{df}=1,71 ; \mathrm{P}<0.001$ for the increment $)$.

Variation within females.

Within females there was a relatively high degree of variation in egg size both across a lifetime (mean $\mathrm{CV}=4.44 ; \mathrm{SD}_{\mathrm{cv}}=3.59$; range $0.64-26.29 ; \mathrm{N}_{\text {females }}=80 ; \mathrm{N}_{\text {eggs }}=1360$; year $=1988$ ) and in a single 
Table 1. Effect of male (mate) and female size on mean egg size as a function of egg mass number in the sequence laid. Male + female; multiple regression (d.f. $=2,75$ ). Male (d.f.=1,78), Female (d.f. $=1,76)$ : univariate regression. Increment (d.f.=1,75): increase in explained variation due to addition of male size to regression already including female size.

\begin{tabular}{cccrr}
\hline & Female + Male & Female & Male & Increment \\
\hline Mass 1: & & & & \\
F & 16.68 & 29.83 & 9.24 & 5.13 \\
$\mathrm{R}^{2}$ & 0.33 & 0.28 & 0.11 & 0.05 \\
$\mathrm{P}$ & $<0.001$ & $<0.001$ & $<0.01$ & $<0.05$ \\
Mass 5: & & & & \\
F & 18.88 & 37.69 & 1.42 & 0.45 \\
$\mathrm{R}^{2}$ & 0.34 & 0.33 & 0.02 & $<0.01$ \\
$\mathrm{P}$ & $<0.001$ & $<0.001$ & $>0.05$ & $>0.05$ \\
& & & & \\
Mass 10: & & & & $<0.01$ \\
$\mathrm{~F}$ & 9.92 & 20.10 & 2.89 & $<0.01$ \\
$\mathrm{R}^{2}$ & 0.21 & 0.21 & 0.04 & $>0.05$ \\
$\mathrm{P}$ & $<0.001$ & $<0.001$ & $>0.05$ & \\
Mass 15: & & & & 0.76 \\
$\mathrm{~F}$ & 0.28 & 0.24 & 0.50 & $>0.05$ \\
$\mathrm{R}^{2}$ & 0.02 & 0.01 & 0.02 & \\
$\mathrm{P}$ & $>0.05$ & $>0.05$ & $>0.05$ & \\
\hline
\end{tabular}

egg mass (mean $\mathrm{CV}=5.29 ; \quad \mathrm{SD}_{\mathrm{cv}}=1.31$; range 2.92-8.04; $\mathrm{N}_{\text {females }}=20 ; \mathrm{N}_{\text {eggs }}=236$; year=1990). Across a lifetime, the $\mathrm{CV}$ for egg size did not differ as a function of egg mass number (KruskalWallis test for rank in $\mathrm{CV} ; \chi^{2}=4.09 ; \mathrm{df}=3 ; \mathrm{P}>0.05$ ).

Multivariate analysis of within-female variation in relative egg size for females laying 15 masses revealed significant effects for placement within the egg mass $\left(\mathrm{F}=6.59 ; \mathrm{df}=1,256 ; \mathrm{R}^{2}=0.03\right)$ and egg mass number (in the sequence laid) $(\mathrm{F}=16.82$; $\mathrm{df}=3,256$; $\mathrm{R}^{2}=0.20$ ) (Table 2). Neither "mother" nor any of the interaction terms was significant $\left(\mathrm{F}<0.02 ; \mathrm{R}^{2}<0.002 ; \mathrm{P}>0.05\right)$.

The mean size of eggs in inner rows was larger than that of eggs in outer rows (In 1988: paired difference $t$-test, $t=3.89 ; \mathrm{N}=80$; $\mathrm{P}<0.001$ for all egg masses. In 1990: paired difference t-test, $\mathrm{t}=3.78, \mathrm{~N}=19, \mathrm{P}<0.01$ for first egg mass laid) (Fig. 3). The mean size of the inner row eggs was significantly positively correlated 

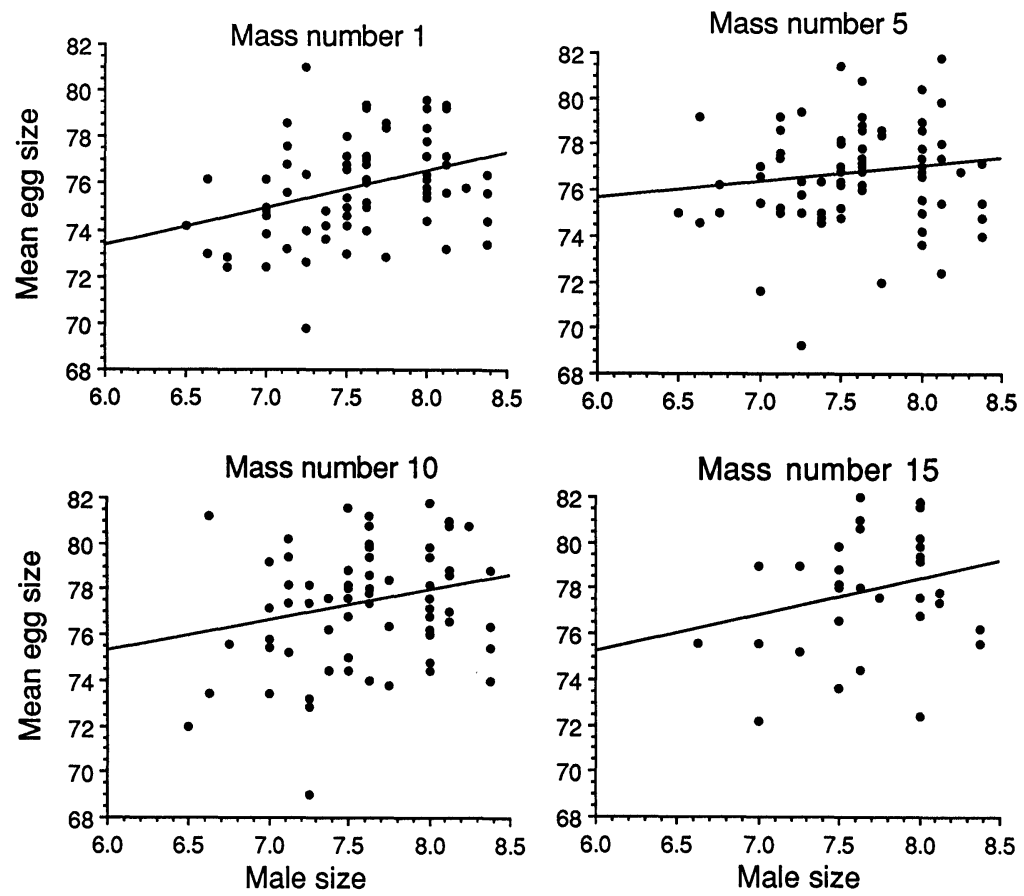

Figure 2. Correlation between male size (width [mm] at humeral angles) and egg size (diameter [0.01 $\mathrm{mm}$ units]) as a function of egg mass number (in the sequence laid).

with the mean size of outer row eggs (Table 2). Thus, females laying larger inner row eggs also laid larger outer row eggs relative to other females. Within a row, egg sizes are correlated; the sizes of the two measured inner row eggs were highly correlated $(r=0.85$; $\mathrm{t}=29.24 ; \mathrm{P}<0.001 ; \mathrm{N}=273)$ as were the sizes of the two measured outer row eggs $(r=0.79 ; \mathrm{t}=22.97 ; \mathrm{P}<0.001 ; \mathrm{N}=273)$.

Relative egg size was larger in later than earlier egg masses (Table 2; Fig. 3). Also, egg mass size (number of eggs) decreased with egg mass number (in the sequence laid) (Kruskal-Wallis test based on rank in mass size, $\chi^{2}=131.41 ; \mathrm{df}=3 ; \mathrm{P}<0.01$; Table 2 ). However, relative egg mass size explained very little of variation in relative mean egg size $\left(\mathrm{F}=4.10 ; \mathrm{df}=1,264 ; \mathrm{R}^{2}=0.02 ; \mathrm{P}=0.04\right.$; comparison across a lifetime). The preceding analysis is 
Table 2. Relationships between egg mass number (in the sequence laid) and mass size (number of eggs), egg size, and intra-mass correlation (r) in egg size. In = inner egg row, Out $=$ outer egg row. In/Out $=$ correlation between mean size of inner and outer row eggs within the same egg mass. In/In and Out/Out = correlation between sizes of two measured eggs from, respectively, inner and outer rows of the same egg mass $(\mathrm{P}<0.05$ for all correlations). $\mathrm{N}=$ number of egg masses sampled. $\mathrm{SD}$ for each mean is given in parentheses.

\begin{tabular}{|c|c|c|c|c|c|c|c|}
\hline \multirow[b]{2}{*}{ Mass } & \multirow[b]{2}{*}{$\mathrm{N}$} & \multirow{2}{*}{$\begin{array}{l}\text { Mass Size } \\
\text { No. eggs }\end{array}$} & \multicolumn{2}{|c|}{ Egg Size $^{1}$} & \multicolumn{3}{|c|}{$\mathrm{r}$} \\
\hline & & & Inner row & Outer row & In/Out & In/In & Out/Out \\
\hline 1 & 80 & $80.61(18.40)$ & $75.76(2.60)$ & $75.15(2.76)$ & 0.73 & 0.84 & 0.74 \\
\hline 5 & 80 & $85.87(18.90)$ & $76.62(2.88)$ & $75.82(2.74)$ & 0.82 & 0.85 & 0.83 \\
\hline 10 & 80 & $66.40(26.00)$ & $77.51 \quad(3.03)$ & $77.20(2.87)$ & 0.85 & 0.87 & 0.81 \\
\hline 15 & 33 & $42.97(20.86)$ & $78.45(3.07)$ & 78.08 (2.77) & 0.68 & 0.87 & 0.79 \\
\hline
\end{tabular}

complicated by the fact that changes in physiological condition in later life may impact egg mass size erratically and much more than does egg size. Therefore, the influence of mass size on mean egg size was examined for the first mass laid using multiple regression models to control for the effect of female size. The following model explained the greatest amount of variation in mean egg size $\left(\mathrm{F}=11.24 ; \quad \mathrm{df}=2,74 ; \quad \mathrm{R}^{2}=0.23 ; \quad \mathrm{P}<0.001\right)$ : mean egg size $[$ range $=69.5-80.5]=75.39-0.22($ mass size $[$ range $=29-117])+$ 0.027 (mass size $) *($ female size $[$ range $=6.38-9.00])$. Step wise regression retains both mass size and the interaction term. Thus, mass size and egg size are significantly negatively correlated.

\section{Progeny fitness and egg size.}

Male and female progeny differed in adult size (female larger) and rate of development (female slower) (Table 3). Therefore, effects of egg size are treated separately for each sex. The sexes did not differ, however, with regard to egg size, although the interaction (mother)*(sex) was significant (Table 3 ). Location within the egg mass did not differ by sex (Kruskal-Wallis test, $\chi^{2}=0.21$; $\mathrm{df}=1 ; \mathrm{P}>0.05$ ). 


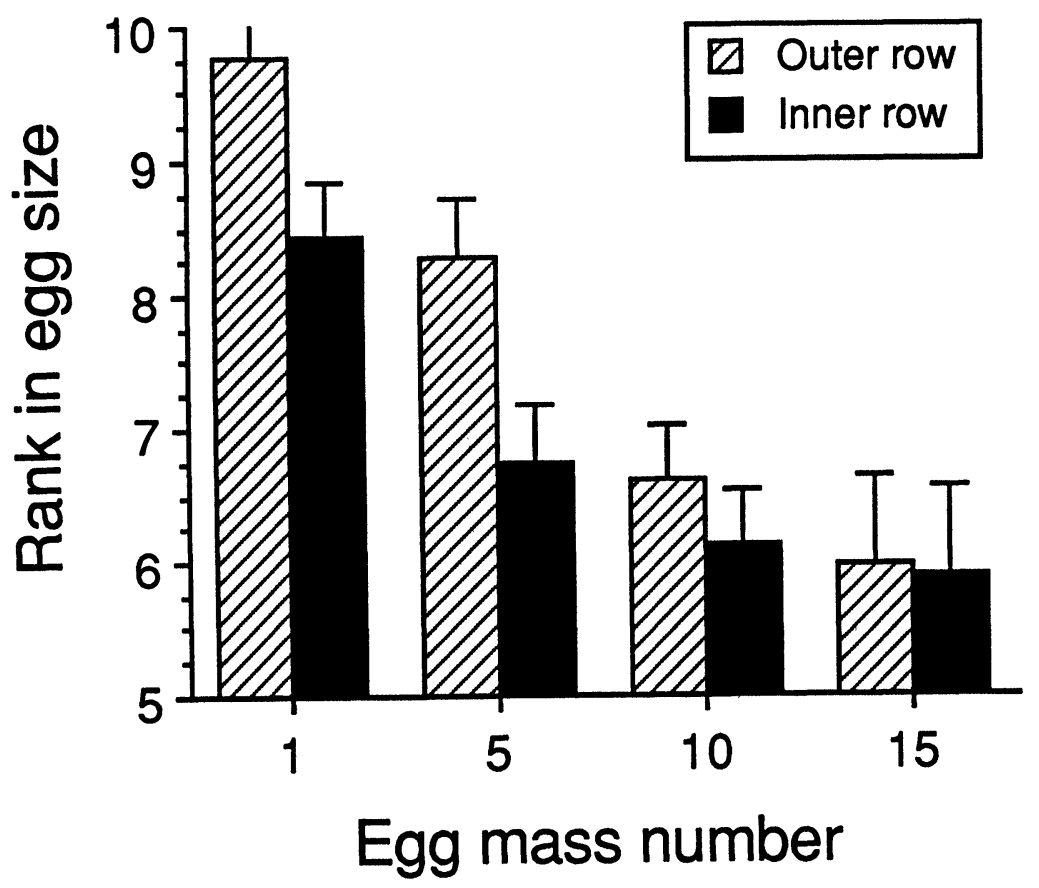

Figure 3. Rank in egg size across a lifetime as a function of location within the egg mass (inner or outer egg row) and egg mass number (in the sequence laid).

For both males and females, egg size within an egg mass was significantly positively correlated with adult size and significantly negatively correlated with development time (Table 4; Fig. 4 and 5 ). The effect of egg size on adult size differed by sex (i.e. intercept of the regression was higher in females; $\mathrm{F}=28.80 ; \mathrm{df}=1,111$; $\mathrm{P}=0.001$ in ANCOVA model: adult size $=$ constant + egg size + mother + sex $)$. Both egg size $(\mathrm{F}=42.85 ; \mathrm{df}=1,111 ; \mathrm{P}<0.001)$ and mother $(\mathrm{F}=2.88 ; \mathrm{df}=9,111 ; \mathrm{P}=0.004)$ had significant effects in this model. This may reflect that females have, on average, longer development time and, therefore, can achieve larger adult size for a given egg size. In an ANCOVA model which also incorporated the interaction between sex and egg size, the interaction was not significant ( $\mathrm{F}-1.31 ; \mathrm{df}=1,110 ; \mathrm{P}>0.05)$, indicating homogeneity of slopes. Similarly, the intercept of the regression of egg size on 
Table 3. ANOVA of effect of sex and mother on progeny traits: (A) adult size, (B) development time, and (C) egg size.

\begin{tabular}{llrrrr}
\hline & Source of Variation & DF & MS & F & P \\
\hline A. Adult size: & sex & 1 & 32.60 & 81.69 & $<0.001$ \\
& mother & 17 & 0.54 & 1.14 & 0.326 \\
& sex*mother & 17 & 0.33 & 0.83 & 0.656 \\
& error & 121 & 0.40 & - & - \\
B. Development: & sex & 1 & 122.34 & 9.54 & 0.002 \\
& mother & 17 & 16.02 & 1.25 & 0.237 \\
& sex*mother & 17 & 13.02 & 1.02 & 0.447 \\
& error & 121 & 12.82 & - & - \\
C. Egg size: & sex & 1 & 63.39 & 3.80 & 0.054 \\
& mother & 17 & 42.65 & 2.56 & 0.002 \\
& sex*mother & 17 & 29.52 & 1.77 & 0.040 \\
& error & 121 & 16.69 & - & - \\
\hline
\end{tabular}

development time was higher in females $(\mathrm{F}=64.26$; $\mathrm{df}=1,111$; $\mathrm{P}<0.001)$ while mother $(\mathrm{F}=5.08 ; \mathrm{df}=9,111 ; \mathrm{P}<0.001)$ and egg size $(\mathrm{F}=58.99 ; \mathrm{df}=1,111 ; \mathrm{P}<0.001)$ had significant effects.

Among males, individuals derived from inner row eggs were larger as adults than those from outer row eggs (analysis based on relative measures, $\mathrm{F}=29.35 ; \mathrm{df}=1,56 ; \mathrm{P}<0.001 ; \mathrm{R}^{2}=0.47$; neither mother nor the interaction between location and mother were significant). Also, males derived from inner row eggs developed faster than those from outer row eggs $(\mathrm{F}=98.79 ; \mathrm{df}=1,56 ; \mathrm{P}<0.001$; $\mathrm{R}^{2}=0.34$ for effect of location). Here, there were also significant effects for mother $\left(\mathrm{F}=2.58 ; \mathrm{df}=11,56 ; \mathrm{P}=0.01 ; \mathrm{R}^{2}=0.10\right)$ and the interaction (mother)*(location) $(\mathrm{F}=10.00 ; \mathrm{df}=11,56 ; \mathrm{P}<0.001$; $\left.\mathrm{R}^{2}=0.38\right)$. These location effects may reflect the greater average size of eggs in the mass interior (ANOVA of egg size: Location, $\mathrm{F}=47.30 ; \mathrm{df}=1,56 ; \mathrm{P}<0.001 ; \mathrm{R}^{2}=0.34$. Interaction with mother, $\mathrm{F}=2.23 ; \mathrm{df}=11,56 ; \mathrm{P}=0.025 ; \mathrm{R}^{2}=0.18$ ). Sample sizes for females were insufficient to permit corresponding analyses.

Relative adult size and development time were significantly negatively correlated in males $(\mathrm{F}=19.07 ; \mathrm{df}=1,65 ; \mathrm{P}<0.001$; $\mathrm{R}^{2}=0.22$; effect of mother was nonsignificant; Fig. 6) and females 
Table 4. ANOVA of effect of egg size and mother on (A) adult size and (B) development time in (1) males and (2) females. For each mother, all measures have been converted to relative values by dividing by the mean of the mother. The effect of relative measures is to de-emphasize between-mother effects due to differences in scale (Contrast effects of mother in Tables 4 and 5). Proportion of variation explained, $\mathrm{R}^{2}$, is: male size, 0.38 ; female size, 0.53 ; male development time, 0.68 ; female development time, 0.71 .

\begin{tabular}{lllllll}
\hline Source of Variation & DF & MS & F & P \\
\hline
\end{tabular}

A. Adult size,

$\begin{array}{llrrrr}\text { 1. Males: } & \text { egg size } & 1 & 0.008 & 8.87 & 0.004 \\ & \text { mother } & 11 & 0.002 & 1.90 & 0.058 \\ & \text { egg size*mother } & 11 & 0.002 & 1.91 & 0.057 \\ & \text { error } & 56 & 0.001 & - & - \\ \text { 2. Females: } & \text { egg size } & 1 & 0.050 & 44.47 & <0.001 \\ & \text { mother } & 9 & <0.001 & <0.001 & 1.000 \\ & \text { egg size*mother } & 9 & <0.001 & <0.001 & 1.000 \\ & \text { error } & 40 & 0.001 & - & -\end{array}$

B. Time,

\begin{tabular}{llrrrc} 
1. Males: & egg size & 1 & 0.203 & 74.04 & $<0.001$ \\
& mother & 11 & 0.012 & 4.52 & $<0.001$ \\
& egg size*mother & 11 & 0.012 & 4.54 & $<0.001$ \\
& error & 56 & 0.003 & - & - \\
2. Females & egg size & 1 & 0.260 & 95.38 & $<0.001$ \\
& mother & 9 & $<0.001$ & $<0.001$ & 1.000 \\
& egg size*mother & 9 & $<0.001$ & $<0.001$ & 1.000 \\
& error & 40 & 0.003 & - & - \\
\hline
\end{tabular}

$\left(\mathrm{F}=52.70 ; \mathrm{df}=1,40 ; \mathrm{P}<0.001 ; \mathrm{R}^{2}=0.57\right.$; effect of mother was nonsignificant). In the best multivariate model predicting adult size of females $\left(R^{2}=0.70\right)$, time $(F=14.55 ; d f=1,38 ; P<0.001)$, egg size $(\mathrm{F}=11.01 ; \mathrm{df}=1,38 ; \mathrm{P}=0.002)$, and their interaction $(\mathrm{F}=13.11$; $\mathrm{df}=1,38 ; \mathrm{P}=0.001$ ) had significant effects while the effect of mother was nonsignificant $(\mathrm{F}=0.61 ; \mathrm{df}=9,38 ; \mathrm{P}>0.05)$. The best model for males $\left(\mathrm{R}^{2}=0.50\right)$ included mother and its interactions with development time and egg size. However, none of the individual sources of variation were significant $(F=1.39-1.89$; $\mathrm{df}=11,46 ; \mathrm{P}>0.05)$. 


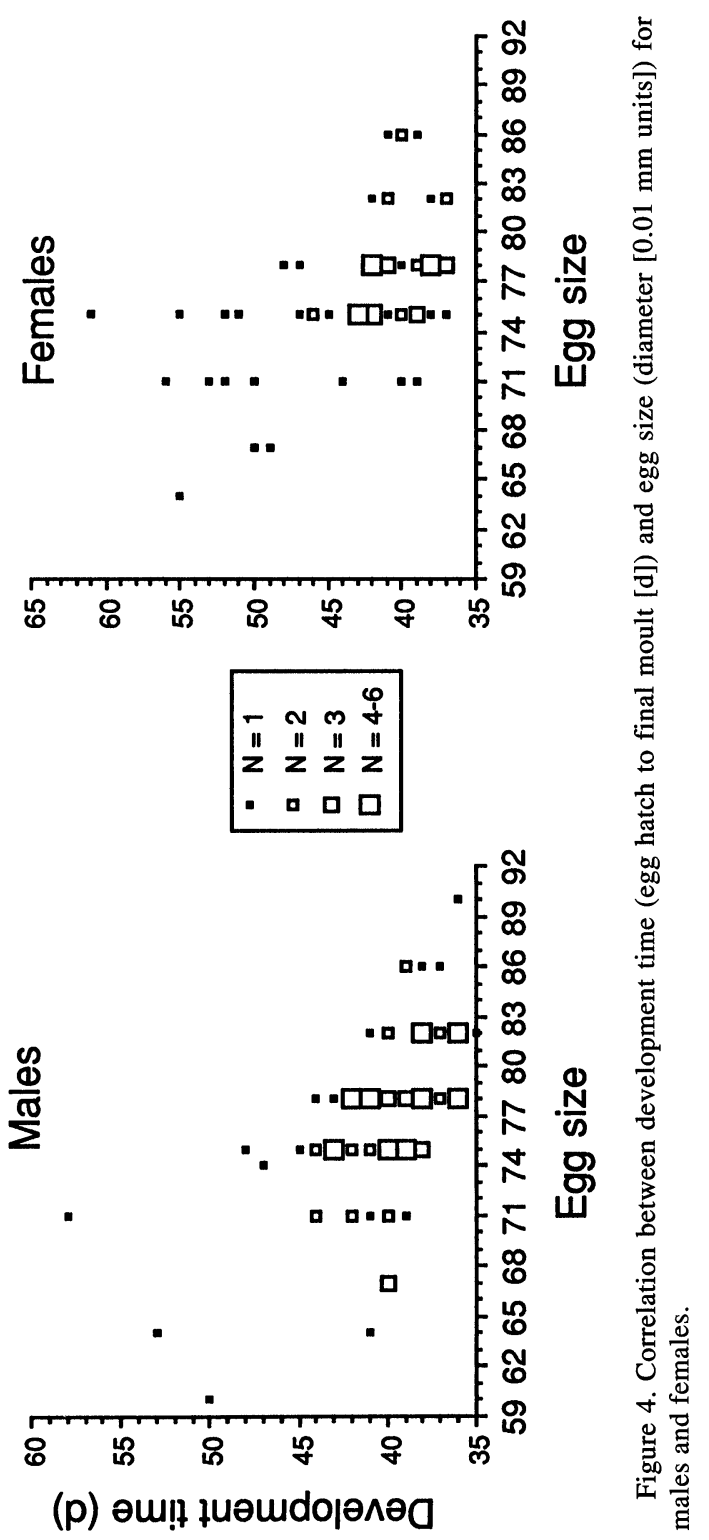




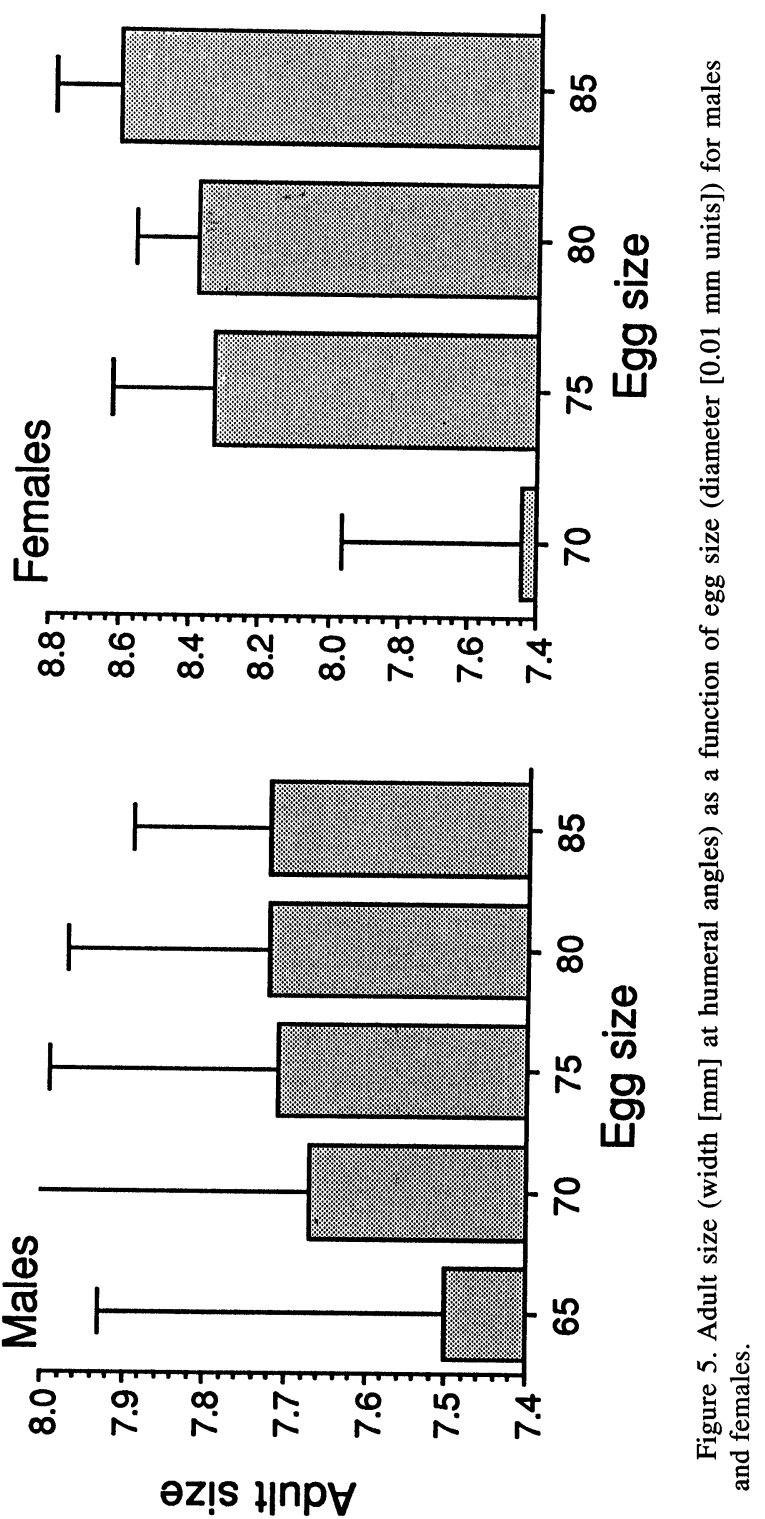




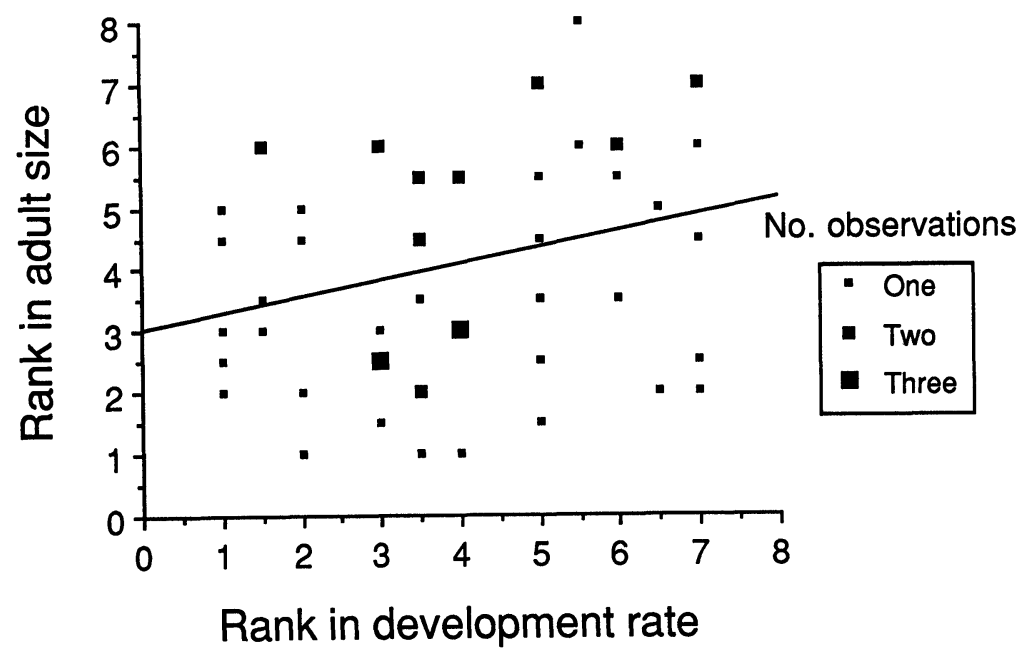

Figure 6. Rank in size of adult male progeny of females having 6-8 sons as a functon of rank in development time. The number of sons is limited to 6-8 so that artifactual correspondence of high ranks is not introduced by the inclusion of females with few sons.

In 1990, mean egg size varied significantly between females $\left(\mathrm{F}=3.39 ; \mathrm{df}=19,219 ; \mathrm{P}<0.001 ; \mathrm{R}^{2}=0.23\right)$. Differences between females in egg size were associated with differences among their progeny in development time and size (Table 5). The slope of the regression of egg size on development time and the intercept of the regression varied as a function of mother (Table 5; Fig. 7). Mother had a similar effect on the regression between egg size and adult size (Table 5: Fig. 8). It is important to note that there is no significant additive genetic variation for size under the experimental conditions (McLain, 1991).

\section{Survival under different conditions.}

Under benign conditions, neither survival of nymphs to adulthood $(\mathrm{F}=2.28 ; \mathrm{df}=1,199 ; \mathrm{P}>0.05)$ nor the interaction between survival and mother $(\mathrm{F}=0.13 ; \mathrm{df}=19,199 ; \mathrm{P}>0.05)$ was a significant predictor of egg size in an ANCOVA model. Mother did have a significant effect $(\mathrm{F}=3.15 ; \mathrm{df}=19,199 ; \mathrm{P}<0.001)$. However, survival rate was greater for nymphs derived from inner row eggs 
Table 5. Effect of mother and egg size on (A) development time and (B) adult size of (1) male and (2) female progeny. Proportion of variation explained, $R^{2}$, is: male development time, 0.78; female development time, 0.89; male size, 0.52; female size, 0.77 .

$\begin{array}{llllll}\text { Source of Variation } & \text { DF } & \text { MS } & \text { F } & \text { P }\end{array}$

A. Time,

1. Male

$\begin{array}{llrccc}\text { 1. Males: } & \text { mother } & 11 & 25.33 & 5.53 & <0.001 \\ & \text { egg size } & 1 & 346.01 & 75.58 & <0.001 \\ & \text { mother*egg size } & 11 & 23.48 & 5.13 & <0.001 \\ & \text { error } & 56 & 4.58 & - & - \\ \text { 2. Females: } & \text { mother } & 9 & 11.27 & 2.91 & 0.013 \\ & \text { egg size } & 1 & <0.001 & <0.001 & 1.000 \\ & \text { mother*egg size } & 11 & 10.47 & 2.70 & 0.019 \\ & \text { error } & 31 & 3.88 & - & -\end{array}$

B. Size,

$\begin{array}{llrccc}\text { 1. Males: } & \text { mother } & 11 & 0.45 & 2.00 & 0.046 \\ & \text { egg size } & 1 & 1.90 & 8.50 & 0.005 \\ & \text { mother*egg size } & 11 & 0.41 & 1.82 & 0.072 \\ & \text { error } & 56 & 0.22 & - & - \\ \text { 2. Females } & \text { mother } & 9 & 0.64 & 3.03 & 0.010 \\ & \text { egg size } & 1 & <0.001 & <0.001 & 1.000 \\ & \text { mother*egg size } & 9 & 0.60 & 2.83 & 0.015 \\ & \text { error } & 31 & 0.21 & - & -\end{array}$

than for nymphs from outer row eggs (Kruskal-Wallis test, $\left.\chi^{2}=4.35 ; \mathrm{df}=1 ; \mathrm{P}=0.04\right)$.

In contrast, under harsh conditions, survival of nymphs to adulthood was a significant predictor of egg size $(\mathrm{F}=5.65 ; \mathrm{df}=1,141$; $\mathrm{P}=0.027)$ as was mother $(\mathrm{F}=4.15 ; \mathrm{df}=14,141 ; \mathrm{P}<0.001)$. The interaction between survival and mother was not significant $(\mathrm{F}=1.74$; $\mathrm{df}=14,141 ; \mathrm{P}>0.05)$. Survival rate did not differ for individuals derived from inner versus outer row eggs (Kruskal-Wallis test; $\chi^{2}=3.07 ; \mathrm{df}=1 ; \mathrm{P}=0.08$ ).

Egg size and hatch rate.

Inner and outer row eggs did not differ in the degree to which paired hatched and unhatched eggs varied in size when egg masses 


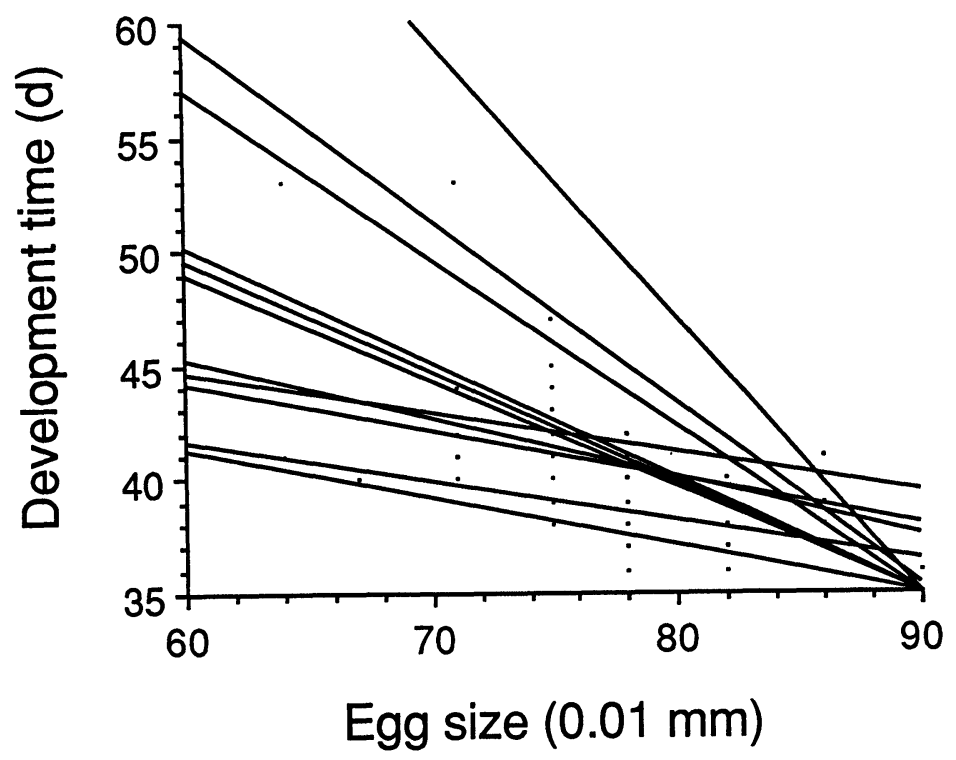

Figure 7. Illustration that the correlation between egg size and development time varies among females (mothers). Graph depicts the development time for males as a function of egg size for all females producing at least 4 sons each.

were developed under humidity-restricted conditions $(\mathrm{F}=0.09$; $\left.\mathrm{df}=1,72 ; \mathrm{R}^{2}=0.001 ; \mathrm{P}=0.76\right)$. Therefore, results from inner and outer row eggs are lumped. Hatched eggs were significantly larger than unhatched eggs (paired-difference $t$-test; $t=5.15 ; \mathrm{P}<0.001$ ).

\section{Pattern of egg laying.}

Eggs are deposited in paired, parallel rows that obliquely approach the long axis of the egg mass (Fig. 9). Once two rows on one side of the axis are laid, two mirroring rows are placed on the other side. The latter half of the mass to be laid is more precisely arranged since every egg laid touches two others at the moment of oviposition. For the first half of the mass, some irregularity can occur since the outer egg on any row touches only one other egg when laid. Females use their hind tarsi and abdomen to feel the location of other eggs before continuing deposition. Note that 


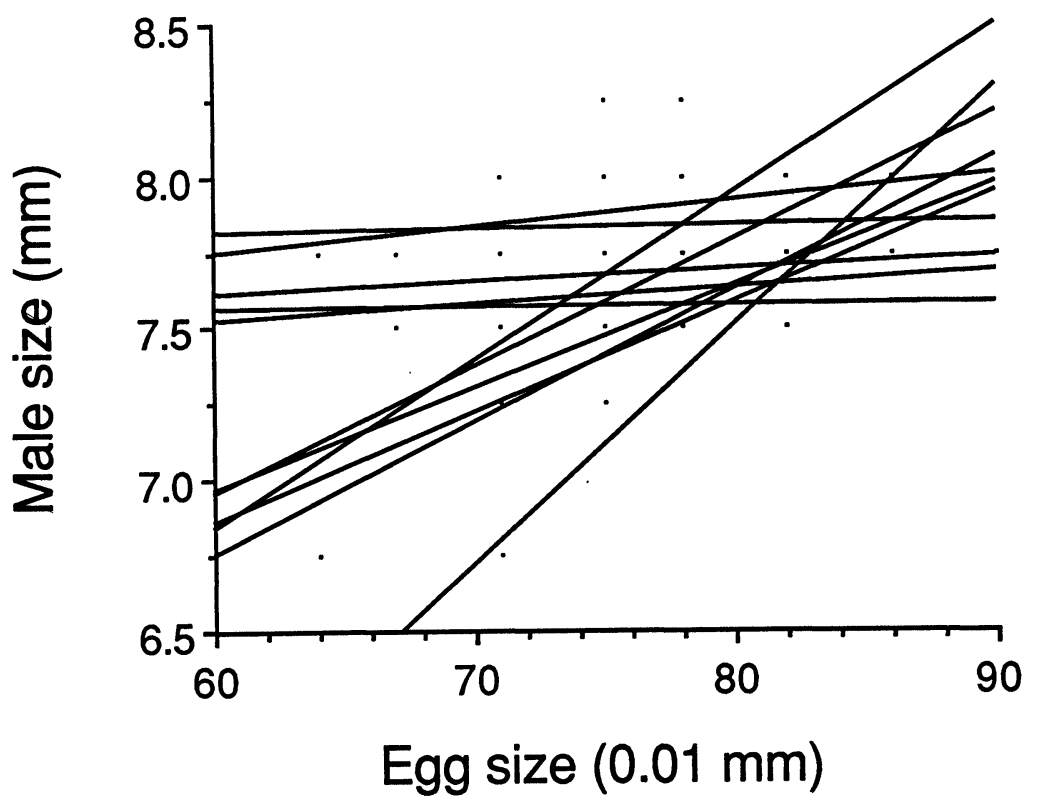

Figure 8 . Illustration that the correlation between egg size and adult size varies among females (mothers). Graph depicts the size of adult males as a function of egg size for all females producing at least 4 sons each.

females must move across half the mass to initiate a new pair of parallel rows, indicating the ability to precisely assess the location of previously laid eggs. Females average just under one minute per egg laid. After completing a mass, females stand "guard" over the eggs from 5 minutes to several hours.

\section{Age-dependent death and egg size.}

We analyze a simple model developed only to determine if a rise in the probability of death, such as might occur with aging, selects for a facultative increase in investment per egg when clutch size is constant. We assume that to invest additional resources per gamete, females increase their mortality risk for the near future and are, therefore, likely to lay fewer masses as investment per egg increases. In southern green stink bugs, the probability of laying a successive mass does decrease for later clutches (McLain et al., 1990a), coincident with an increase in egg size. 

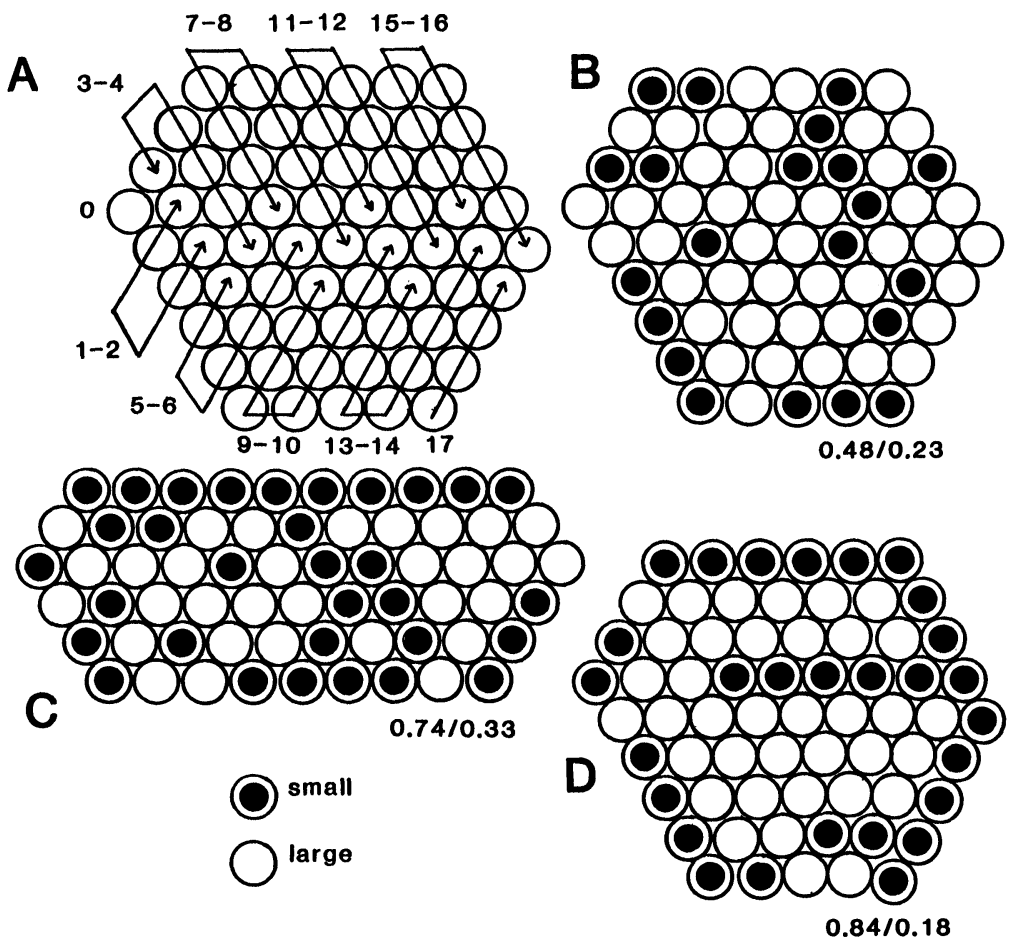

Figure 9. Arrangement of eggs within an egg mass. (A) Pattern of egg deposition giving rise to the typical hexagonal array of eggs. Numbers beside vectors identify the order in which rows were laid while vector length corresponds to the number of eggs laid. Point 0 is the initial egg laid. (B-D) Simulations of the arrangement of large and small eggs if females terminate a row and initiate a new row upon encountering a small egg (see Discussion for constraints on the hypothetical behavior pattern). Ratios indicate proportion of small eggs in outer (numerator) and inner (denominator) rows. (B) Small eggs occur at random and at a frequency of 0.33. (C) Small eggs occur at random and at a frequency of 0.50. (D) Small eggs occur regularly at a frequency of 0.33 ; last eggs to mature are small.

We assume that females acquire resources and allocate them to gametes and various maintenance functions. Total resources allocated to gametes is ct, where $t$ is the investment per gamete and $c$ is clutch size (a constant). Also, we assume that the survival probability of nymphs, $f(t)$, is a positive function of $t$, with an asymptote of 1 while the survival probability of females, $p(t)$, is a declining function of $t$ (because clutch size is constant and 
resources are limiting); $f(t)=1-k /[k+b t]$ and $p(t)=1-t / j-d$ where $b, d, j$ and $k$ are constants. The term $d$ represents the mortality source independent of investment in gametes and has a value between 0 and 1 . The question we address is whether or not $t$ should increase if the value of $\mathrm{d}$ increases at some point in time; i.e. should females invest more per gamete as probability of survival decreases.

Female fitness is $w_{t}=c f(t) p(t)+c f(t) p(t)^{2}+\ldots+c f(t) p(t)^{n}$, the probability of surviving to lay $n$ clutches of size $c$ with offspring of fitness $f(t)$. This infinite series reduces to:

$$
\begin{aligned}
& \mathrm{w}_{\mathrm{t}}=\mathrm{cf}(\mathrm{t}) \mathrm{p}(\mathrm{t}) /[1-\mathrm{p}(\mathrm{t})] \text { which is maximized when } \\
& \mathrm{t}=\left[\left\{\mathrm{d}^{2} \mathrm{j}^{2} \mathrm{k}^{2}+\left(\mathrm{d}-\mathrm{d}^{2}\right)\left(b \mathrm{j}^{3} \mathrm{k}+\mathrm{j}^{2} \mathrm{k}^{2}\right)\right\}^{0.5}-\mathrm{djk}\right] /[\mathrm{bj}+\mathrm{k}] .
\end{aligned}
$$

Note that as long as $\left(d-d^{2}\right)>0$ (i.e. $\left.0<d<1\right)$, $t$ increases as a function of $d$. Thus, females experience selection to increase egg size, even at the expense of future reproduction, when investmentdependent mortality increases.

\section{DISCUSSION}

Egg size and progeny fitness.

Fitness of genotypes influencing egg size can be modeled as the product of fitness components influenced by egg size; number of eggs, egg hatch rate, survival rate from egg hatch to adulthood, number of grand progeny produced by adult offspring (via ability to survive, compete for food or mates, etc.). The results demonstrate that egg size is positively correlated with: (1) egg hatch rate (under conditions of low humidity), (2) survival from egg hatch to adulthood (under conditions of food deprivation), (3) development rate, and (4) size of adult progeny. Progeny that are larger as adults are expected to experience greater reproductive success due to the correlations between female size and fecundity (McLain et al., 1990a) and between male size and mating/fertilization success (McLain, 1980; McLain, 1985; McLain et al., 1990b). Faster rates of development may translate into reduced exposure to mortality agents during development and increased opportunities to reproduce as an adult. Also, other fitness components may be positively correlated with egg size (reviewed in McGinley et al., 1987; Shine, 1989; but for exceptions see Karlsson and Wiklund, 1984, 1985; 
Wiklund and Karlsson, 1984; Wiklund and Persson, 1983). Thus, variation in egg size within and among females can have important fitness consequences and, in the cases examined, larger eggs confer a fitness advantage. Selection favoring larger eggs is further suggested by the observation that in older females egg size does not decrease (see also Gaugler and Brooks, 1975; Price and Liou, 1989) although total allocation to reproduction decreases by several fold (McLain et al., 1990a).

Greater nutrient stores in larger eggs may permit nymphs to hatch at a larger size, resulting in increased mobility in the search for food and increased stamina in the absence of food. Also, larger eggs may be more resistant to drying under conditions of low relative humidity.

Variation in egg size between females.

No doubt there are constraints on the evolution of ever larger eggs including the number of progeny that could then be produced on a limited allocation to reproductive effort, the ability of a small body to lay large eggs, and correlations between egg size and attractiveness to predators and parasites. Given opposing selective pressures, questions arise: (1) is an optimal egg size favored, (2) do identified selection pressures on egg size vary in magnitude or direction from one environment to another, from female to female, or during a lifetime, and (3) do females manipulate egg size in response to changing conditions? If selection pressures vary and if females can manipulate egg size in response to changing pressures, then at least some adaptive variation in egg size is expected within and/or between females.

Egg size varies within and between females. The magnitude of variation in egg size is comparable to that for body size, relative to respective mean size. Typically, relative variation in egg size is small compared to variation in body characters (Capinera, 1979). This suggests that there is not strong stabilizing selection for an optimal egg size (see Smith and Fretwell, 1974). Since variation within females accounts for about one-half of the observed variation in egg size, it is unlikely that different single optima are strongly selected in different females (see Parker and Begon, 1986). Single optima may be selectively favored if: (1) egg size is positively and consistently correlated with progeny fitness, and (2) 
egg size is inversely correlated with the number that can be produced (Smith and Fretwell, 1974). The results demonstrate that egg size is positively correlated with components of offspring fitness (mortality rate, size, development time) and that there is a significant, if only weak, relationship between egg size and number of eggs per mass. Thus, variation in egg size requires examination.

Variation within females may represent bet-hedging, a strategy in which mean offspring fitness in any single environment is sacrificed in favor of high variance in offspring fitness across environments. Bet-hedging represents selection for higher geometric mean fitness across multiple, randomly-encountered environments (Philippi and Seger, 1989). Thus, if larger eggs were favored in one environment and small eggs in another, females might be selected to produce both large and small eggs if the environment changes or if it is not possible to predict or ascertain relevant environmental parameters. Also, canalizing selection for an optimal egg size may be weakened by variation within any given environment (Capinera, 1979; Kaplan and Cooper, 1984; McGinley et al., 1987).

Variation between females accounts for approximately one-half of the total variation in egg size. Female health and physiological state are implicated in between-female variation in egg size since the slope between egg size and female size varies as a function of the ultimate number of masses laid (which is proportional to longevity; McLain et al., 1990a). Healthier females may have more resources to invest in eggs (e.g. Moore and Singer, 1987). Differences in physiological condition may also explain between-female variation in the correlation between egg size and progeny size or development rate even when the egg mass number (in the sequence laid) is held constant.

Approximately one-third of the between-female variation is explained by differences in female size and may, therefore, simply reflect isometric scaling (Wiklund et al., 1987; Shine, 1988). Isometric scaling can, nonetheless, have multiple effects on evolutionary dynamics, affecting the rate and direction of phenotypic change in adaptive and maladaptive ways, if egg size influences offspring fitness (Kirkpatrick and Lande, 1989). However, such scaling does not explain the observation that egg size loses its 
correlation with body size for later masses and that most females produce larger eggs in later masses.

If the rate at which food is ingested and converted to eggs varies with female size, larger females may experience selection to produce larger eggs (Parker and Begon, 1986; Begon, 1985), especially if (1) absolute and relative egg size affect progeny fitness (e.g. Wellington, 1957; Greenblatt and Witter, 1976) and (2) siblings (from the same egg mass) are more likely to compete for food among themselves than with offspring from other egg masses. Intra-mass competition is probably of common occurrence since oviposition frequently occurs on small, widely dispersed clusters of host plant (e.g. wild mustard or radish, Brassica spp.). Egg size is positively correlated with mate size for the first egg mass produced, indicating nutrient transfer from male to female (see McLain et al., 1990a) and, by inference, that the quality or rate of nutrient intake influences egg size.

Manipulation of egg size provides evidence for selective constraint and adaptation in egg size. Females produce larger eggs under conditions of higher adult density. Under conditions of variable density (2-7 females/liter; $\mathrm{CV}=29.79)$, density explains over twice as much between-female variation in egg size as does female size $(\mathrm{CV}=6.26)$. Under high density, females may experience selection pressure to produce larger eggs if this in turn leads to nymphs that are larger and more competitive or that are better able to endure periods of food shortage.

Variation in egg size within females.

Egg size variation within a single egg mass is comparable to that observed between females (see also Capinera et al., 1977; Wellington and Maelzer, 1967). Variation in egg size is associated with differential provisioning and may simply reflect availability of resources during the period when ova are maturing. This proximate explanation is unlikely to apply to the present case since females experienced a food supply of consistently high quality. Thus, egg size variation, which leads to variation in offspring size and developmental rate, may reflect a history of selection for bethedging imposed by habitats that vary in space or time (Capinera, 1979; Kaplan and Cooper, 1984; McGinley et al., 1987). Variation in offspring size due to egg size variation may give rise to 
offspring variation in mobility, social behavior, and resource needs (e.g. Wellington, 1964, 1965; Leonard, 1970a,b; Capinera and Barbosa, 1976; Uvarov, 1961; Sinervo and Huey, 1990). Again, canalizing selection for an optimal (i.e. constrained) egg size may be weakened by environmental variation (e.g. McGinley et al., 1987).

An adaptive role for egg size variation within females is indicated by pattern in egg size variation. Eggs on outer rows are smaller than those within an egg mass. Also, eggs laid in later egg masses are larger.

Nymphs from outer row eggs are less likely to survive than those from eggs located within the mass. Thus, selection should favor less investment in outer row eggs or favor placing in outer rows those eggs receiving less provisioning. Outer row eggs may be more susceptible to variation in microclimate (although egg hatch did not vary between inner and outer row eggs under reduced humidity conditions). Such susceptibility could have selected for the tightly packed, hexagonal array of eggs in the typical Nezara viridula egg mass. Also, small size may be favored in outer row eggs since these are more susceptible to predation or parasitization (Hokyo and Kiritani, 1966; Hokyo et al., 1966). $N$ viridula eggs are attacked by parasitic scelionid wasps and a variety of predators (Buschman and Whitcomb, 1980; Orr et al., 1986; Moreira and Becker, 1986a,b,c). Since egg mortality rates due to predators and parasites may exceed 40\% (Moreira and Becker, 1986a), selection to reduce investment in susceptible offspring may be strong.

The pattern of egg deposition permits females to bias the placement of relatively small eggs. A simple behavioral mechanism is capable of biasing the outer rows with smaller eggs provided, of course, that females can assess egg size and make decisions based on the assessment (Fig. 9B-D). As an ovipositing female approaches the mass axis, she needs to assess the relative size of the next egg to be laid. If the egg is small, she could cut the row short and begin a new row, either parallel or across the axis, with the small egg (The mirroring rows would then be compensatorily longer and no gap would be present in the egg mass). Females with a large egg at the axis could cross the axis instead of beginning a new row, provided that continuing across the axis still permits placement of the egg adjacent to two other eggs. As the proportion of small eggs increases (e.g. 33\% to 50\% in Fig. 9C), the potential 
to bias the outer row increases. Also, long, narrow masses with shorter oblique, parallel rows provide more opportunity for decisions and should on average allow greater bias (This is observed). If small eggs are encountered regularly instead of at random the potential for bias is further increased (Fig. 9D). Finally, the outer rows on two of the faces of a hexagonal mass are the last to be laid. Thus, if the last eggs produced are smaller, some bias will occur without decision making by the female. If the number of these small eggs is relatively large, then a more rounded (versus elongate) mass would lead to a greater bias of small eggs on the mass periphery.

Egg size increased in later egg masses and lost its correlation with female size as most females began producing relatively large eggs. This contrasts with other species of insects studied where egg size decreases with maternal age (Jones et al., 1982; Murphy et al., 1983; Wiklund and Persson, 1983; Karlsson and Wiklund, 1984, 1985). Also, theoretical models predict declining egg size with age if clutch size is constrained and female mortality is ageindependent (Begon and Parker, 1986). However, in a variety of vertebrates, investment per offspring increases with increasing maternal age when mortality is age-dependent (reviewed in Trivers, 1985). Thus, the fitness consequences of extra investment in current offspring can outweigh reduced ability to invest in future offspring when the probability of future offspring is relatively low.

The model developed above (see Results) indicates that any increase in reproduction-independent mortality selects for greater investment per gamete even if increased investment in gametes further reduces long-term survival of females. There are a number of factors that could cause the probability of survival to decline. Risk of parasitization, and population density increase seasonally (McLain et al., 1990b; Todd, 1989; see also Ives, 1989) while host plant quality may decline. Note that these same factors select for larger egg size (see discussion above). General vigor of females may also decline with age (McLain et al., 1990a), perhaps reflecting prior allocation to both gamete-dependent and -independent physiological demands. 
Conclusions.

Egg size is positively correlated with the survival and potential for reproductive success of progeny under at least some conditions. Yet, egg size varies significantly between and within females. This suggests that conditions favoring relatively large eggs are not consistently encountered and that, therefore, natural selection has favored the production of eggs of variable size. Apparently at least some of the observed variation between and within females reflects an adaptive response to prevailing social and physiological conditions. Prior selection on egg size imposed by habitat variation and mortality agents may further explain variation and patterns of variation in egg size within and between females. Thus, an optimum range in egg size may have been favored as a bet-hedging strategy that, nonetheless, permits adaptive adjustment of mean egg size in response to varying local conditions.

Since much of the variation between individuals in fitness components is attributable to effects of the mother, it appears that egg quality has a component independent of egg size. This may simply reflect genotypic differences among progeny inherited from their mothers. Alternatively, differential nutrient packaging may occur, allowing females a further adaptive response to changing conditions. As of now, there is no evidence that yolk supplies differ as a function of female size or physiological state nor that females optimize the product of nutritive quality and egg number. Nonetheless, if egg nutritional quality varies and impacts components of offspring fitness, selection may effect a balance between nutrient quality and egg number since both quantities would impact limited energy reserves.

\section{SUMMARY}

In the southern green stink bug, Nezara viridula, the coefficient of variation for egg size (diameter) is $98 \%$ that of female size. Differences in egg size among females account for $57 \%$ of the total variation in egg size, with female size accounting for $36 \%$ of the variation between females in mean egg size. Male (mate) size also accounts for some of the between-female variation in egg size. Within-female variation in egg size is associated with placement of eggs in the egg mass; eggs in the interior of masses are larger than those on the periphery (explaining $3 \%$ of variation). An additional 
$20 \%$ of the within-female variation is explained by egg mass number (e.g. first, fifth, tenth, or fifteenth mass laid); eggs in later masses were larger. Larger eggs were more likely to hatch under adverse conditions (lower humidity), whether located within the egg mass or on its periphery. Within a single egg mass, progeny from larger eggs matured more quickly and attained larger size. Survival rate from egg hatch to adulthood was positively correlated with egg size under harsh (mortality $=41 \%$ ) but not benign conditions (mortality $=29 \%$ ). Survival rate was higher for eggs in the interior of masses. Positive correlations between egg size and components of offspring fitness suggest adaptive hypotheses for observed variation in egg size. Laboratory correlation between egg size and population density also suggests that egg size experiences strong selection. Competition for food among offspring, heterogeneity in habitat quality, egg predation, and age-dependent mortality are posited as the selection pressures constraining egg size and variation in egg size.

\section{Literature Cited}

BEGON, M.

1985. Density and individual fitness: asymmetric competition. Br. Ecol. Soc. Symp. 23: 175-194.

BEgON, M. AND G. A. PARKer

1986. Should egg size and clutch size decrease with age? Oikos 47: 293-302.

BusChMAN, L. L. AND W. H. WhitcomB

1980. Parasites of Nezara viridula and other Hemiptera in Florida, USA. Fla. Entomol. 63: 154-162.

CAPINERA, J. L.

1979. Qualitative variation in plants and insects: effect of propagule size on ecological plasticity. Am. Nat. 114: 350-361.

CAPINERA, J. L. AND P. BARBosA

1976. Dispersal of first-instar gypsy moth larvae in relation to population quality. Oecologia 26: 53-60.

CAPInera, J. L., P. Barbosa, AND H. H. HAGEdorn

1977. Yolk and yolk depletion of gypsy moth eggs: implications for population quality. Ann. Entomol. Soc. Am. 70: 40-42.

EDWARDS, A. L.

1985. Multiple regression and the analysis of variance and covariance. New York, W. H. Freeman.

GaUgler, J. A. AND W. M. BRooks

1975. Sublethal effects of infection by Nosema heliothidis in the corn earworm, Heliothis zea. J. Invertebr. Pathol. 26: 57-63.

GreEnblatt, J. A. AND J. A. Witter

1976. Behavioral studies on Malacosoma disstria (Lepidoptera: Lasiocampidae). Can. Entomol. 108: 1225-1228. 
HARRIS, V. E. AND J. W. TODD

1980. Temporal and numerical patterns of reproductive behavior in the southern green stink bug, Nezara viridula (L.) (Hemiptera: Pentatomidae). Entomol. Exp. Appl. 27: 1-10.

HoKYo, N. AND K. KIRITANI

1966. Ovipositional behaviour of two egg parasites, Asolcus mitsuurii Ashmead and Telenomus nakagawaii Watanabe (Hym., Prototrupoidea, Scelionidae). Entomophaga 11: 191-201.

HoKYo, N., M. SHIGA AND F. NAKASUJI

1966. The effect of intra- and inter-specific conditioning of host eggs on the ovipositional behavior of two scelionid egg parasites of the southern green stink bug, Nezara viridula L. Jap. J. Ecol. 16: 67-71.

IVES, A. R.

1989. The optimal clutch size of insects when many females oviposit per patch. Am. Nat. 133: 671-687.

JOHNSON, L. K.

1982. Sexual selection in a brentid weevil. Evolution 36: 251-262.

JoNES, R. E., J. R. HART AND G. D. Bull

1982. Temperature, size and egg production in the cabbage butterfly, Pieris rapae. Aust. J. Zool. 30: 223-232.

KAPLAN, R. H. AND W. S. COOPER

1984. The evolution of developmental plasticity in reproductive characteristics: an application of the "adaptive coin flipping" principle. Am. Nat. 123: 393-410.

KARLSSON, B. AND C. WIKLUND

1984. Egg weight variation and lack of correlation between egg weight and offspring fitness in the wall brown butterfly Lasiommata megera. Oikos 43: 376-385.

1985. Egg weight variation in relation to egg mortality and starvation endurance of newly hatched larvae in some satyrid butterflies. Ecol. Entomol. 10: 205-211.

KIRKPATRICK, M. AND R. LANDE

1989. The evolution of maternal characters. Evolution 43: 485-503.

LEONARD, D. E.

1970a. Effects of starvation on behavior, number of larval instars, and development rate of Porthetria dispar. J. Insect Physiol. 16: 25-31.

1970b. Intrinsic factors causing qualitative changes in populations of Porthetria dispar (Lepidoptera: Lymantriidae). Can. Entomol. 102: 239-249.

McGinley, M. A., D. H. Themme AND M. A. Geber

1987. Parental investment in offspring in variable environments: theoretical and empirical considerations. Am. Nat. 130: 370-398.

MCLAIN, D. K.

1980. Female choice and the adaptive significance of prolonged copulation in Nezara viridula (Hemiptera: Pentatomidae). Psyche 87: 325-336.

1985. Male size, sperm competition, and the intensity of sexual selection in the southern green stink bug, Nezara viridula (Hemiptera: Pentatomidae). Ann. Entomol. Soc. Am. 78: 86-89.

1991. Heritability of size: a positive correlate of multiple fitness components in the southern green stink bug. Ann. Entomol. Soc. Am. 84: 174-178. 
MCLain, D. K., D. L. LANier AND N. B. MaRSH

1990a. Effects of female size, mate size and number of copulations on fecundity, fertility and longevity in the southern green stink bug, Nezara viridula (Hemiptera: Pentatomidae). Ann. Entomol. Soc. Am. 83: 1130-1136.

McLain, D. K., N. B. MarSh, J. R. LopeZ and J. A. Drawdy

1990b. Intravernal changes in the level of parasitization of the southern green stink bug, Nezara viridula (Hemiptera: Pentatomidae), by the featherlegged fly, Trichopoda pennipes: host sex, mating status, and body size as correlated factors. J. Entomol. Sci. 25: 501-509.

Moore, R. A. AND M. C. SINGER

1987. Effects of maternal weight and adult diet on egg weight in the butterfly Euphydryas editha. Ecol. Entomol. 12: 401-408.

MoReIRA, G. R. P. AND M. BECKER

1986a. Mortality of Nezara viridula (Linnaeus, 1758) (Heteroptera: Pentatomidae) in the egg stage in a soybean field: I. All causes of mortality. An. Soc. Entomol. Bras. 15: 271-290.

1986b. Mortality of Nezara viridula (Linnaeus, 1758) (Heteroptera: Pentatomidae) in the egg stage in a soybean field: II. Parasitoids. An. Soc. Entomol. Bras. 15: 291-308.

1986c. Mortality of Nezara viridula (Linnaeus, 1758) (Heteroptera: Pentatomidae) in the egg stage in a soybean field: III. Predators. An. Soc. Entomol. Bras. 15: 309-326.

MurPhy, D. D., A. E. LAUNeR AND P. R. EHRLICH

1983. The role of adult feeding in egg production and population dynamics of the checkerspot butterfly Euphydryas editha. Oecologia 56: 257-263.

Nassbaum, R. A. AND D. L. Schultz

1989. Coevolution of parental care and egg size. Am. Nat. 133: 591-603.

OrR, D. B., J. S. Russin, D. J. BoETHEL AND W. A. JONES

1986. Stink bug (Hemiptera: Pentatomidae) egg parasitism in Louisiana (USA) soybeans. Environ. Entomol. 15: 1250-1254.

PARKer, G. A. AND M. BEGON

1986. Optimal egg size and clutch size: effects of environment and maternal phenotype. Am. Nat. 128: 573-592.

PhILIPPI, T. AND JON SEGER

1989. Hedging one's evolutionary bets, revisited. TREE 4: 41-44.

PRICE, T. AND L. LIOU

1989. Selection on clutch size in birds. Am. Nat. 134: 950-959.

PRICE, P. W. AND M. E. WiLSON

1976. Some consequences for a parasitic herbivore, the milkweed longhorn beetle, Tetraopes tetraophthalmus, of a host-plant shift from Ascelpias syriaca to A. verticillata. Oecologia 25: 331-340.

RichaRds, L. J. AND J. H. MEYERS

1980. Maternal influences on size and emergence time in the cinnabar moth. Can. J. Zool. 58: 1452-1457.

SHINE, R.

1988. The evolution of large body size in females: a critique of Darwin's "fecundity advantage" model. Am. Nat. 131: 124-131.

1989. Alternative models for the evolution of offspring size. Am. Nat. 134: 311-317. 
Sinervo, B. AND R. B. HueY

1990. Allometric engineering: an experimental test of the causes of interpopulation differences in performance. Science 248: 1106-1109.

SOKAL, R. R. AND F. J. ROHLF

1981. Biometry. San Francisco, W. H. Freeman.

SMith, C. C. AND S. D. FRETwell

1974. The optimal balance between size and number of offspring. Am. Nat. 108: 499-506.

STEINWASCHER, K.

1984. Egg size variation in Aedes aegypti: relationship to body size and other variables. Am. Midl. Nat. 112: 76-84.

TodD, J. W.

1989. Ecology and behavior of Nezara viridula. Ann. Rev. Entomol. 34: 273-292.

TRIVERs, R. L.

1985. Social evolution. Menlo Park, CA, Benjamin Cummings.

UVAROV, B. P.

1961. Quantity and quality in insect populations. Proc. Roy. Entomol. Soc. Lond. Ser. C, J. Meet. 25: 52-59.

Wellington, W. B.

1957. Individual differences as a factor in population dynamics: the development of a problem. Can. J. Zool. 35: 293-323.

1964. Qualitative changes in populations in unstable environments. Can. Entomol. 96: 436-451.

1965. Some maternal influences on progeny quality in the western tent caterpillar, Malacosoma pluviale (Dyar). Can. Entomol. 97: 1-14.

Wellington, W. B. AND D. A. MAELZER

1967. Effects of farnesyl methyl ether on the reproduction of the western tent caterpillar, Malacosoma pluviale: some physiological, ecological, and practical implications. Can. Entomol. 99: 249-263.

WIKLUND, C. AND B. KARLSSON

1984. Egg size variation in satyrid butterflies: adaptive vs. historical, "Bauplan", and mechanistic explanations. Oikos 43: 391-400.

1988. Sexual size dimorphism in relation to fecundity in some Swedish satyrid butterflies. Am. Nat. 131: 132-138.

Wiklund, C. AND A. Persson

1983. Fecundity and the relation of egg weight to offspring fitness in the speckled wood butterfly Pararge aegeria, or why don't butterfly females lay more eggs. Oikos 40: 53-63.

WiKLUND, C., B. KARLSSON AND J. FoRSBERG

1987. Adaptive versus constraint explanations for egg-to-body size relationships in two butterfly families. Am. Nat. 130: 828-829.

WILKINSON, L.

1987. Systat: the system for statistics. Evanston, IL, Systat Inc. 

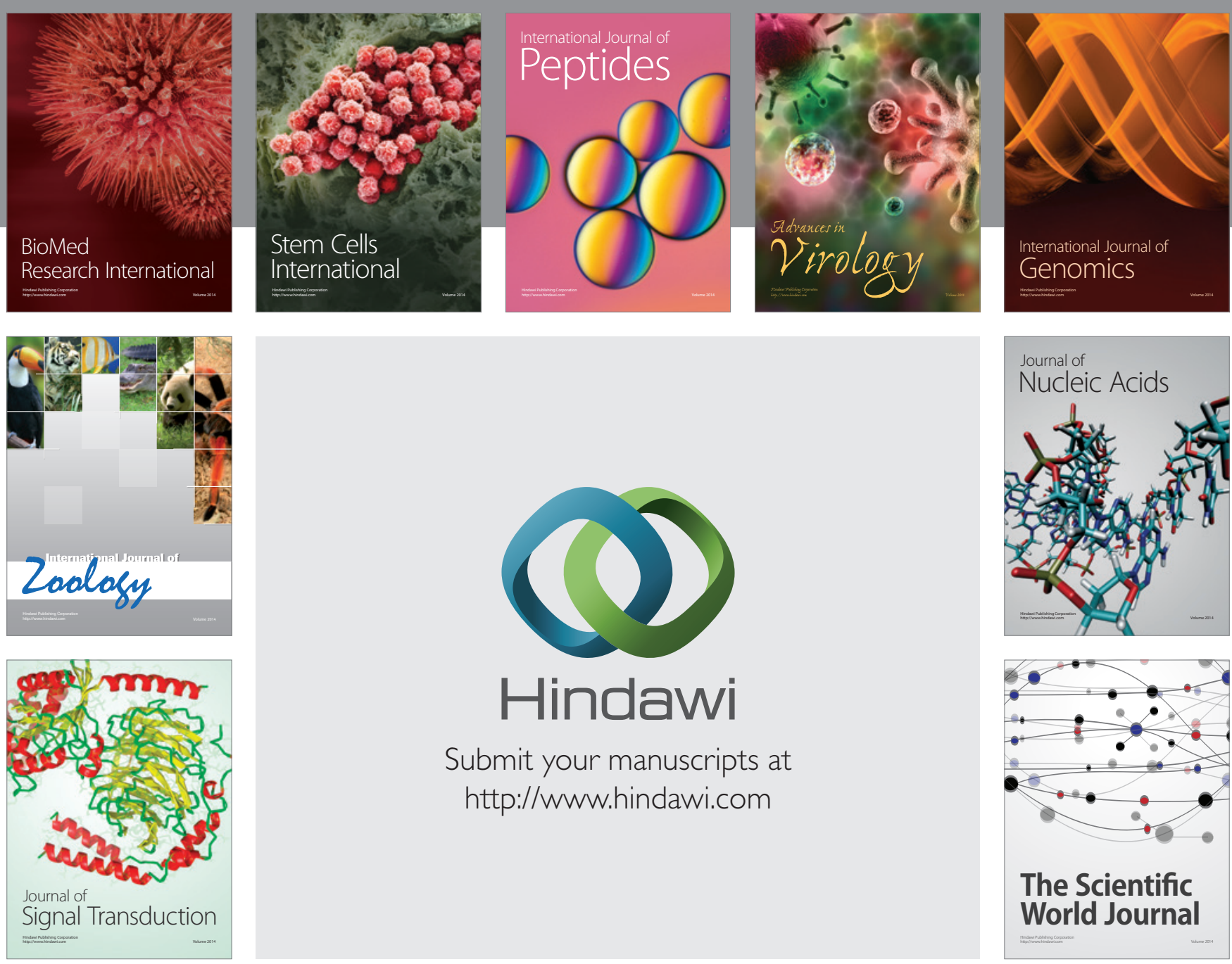

Submit your manuscripts at

http://www.hindawi.com
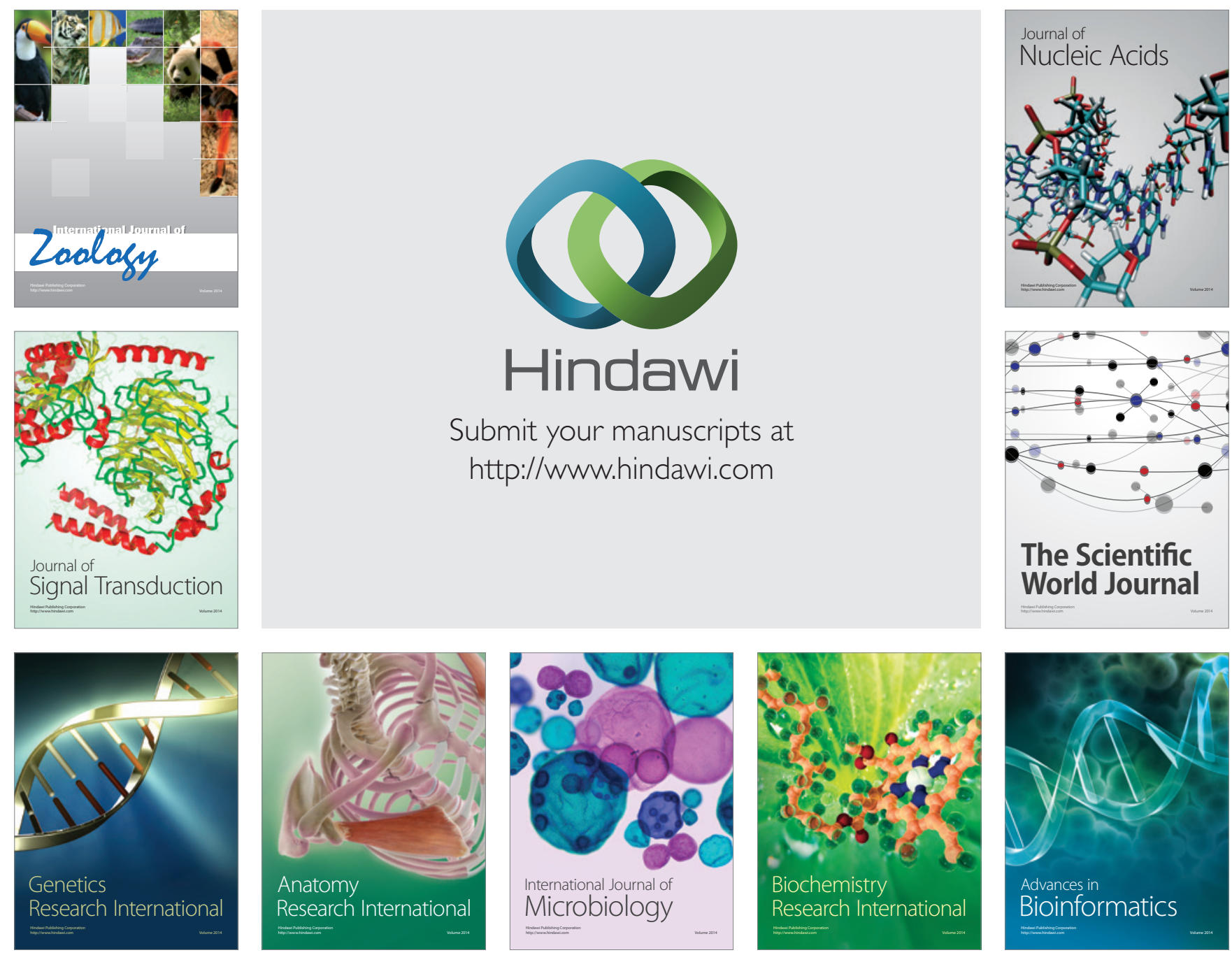

The Scientific World Journal
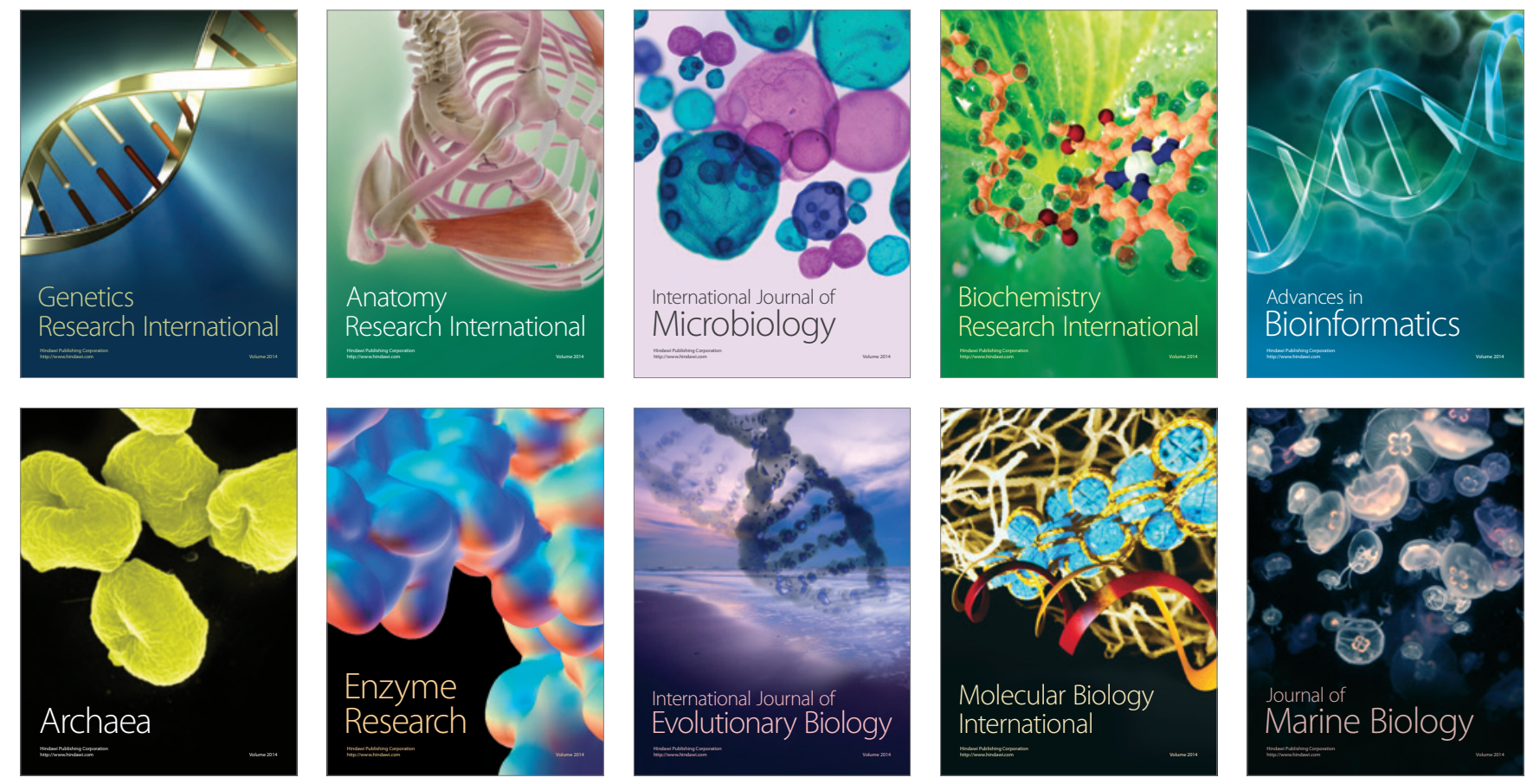